\title{
Structural variation of melt-crystallized PTT during the heating process revealed by FTIR and SAXS
}

\author{
CHEN Zhen \& YAN ShouKe* \\ Institute of Chemistry, Chinese Academy of Sciences, Beijing 100190, China
}

Received March 25, 2012; accepted May 22, 2012; published online December 6, 2012

\begin{abstract}
Time-resolved FTIR, WAXD/SAXS and DSC have been used to investigate the structural variation of non-isothermally crystallized poly(trimethylene terephthalate) (PTT) during the heating process. The three-phase model: the lamellar phase, the mobile amorphous phase (MAP) and the rigid amorphous phase (RAP) between lamellae is suggested to describe the structure of meltcrystallized PTT. According to FTIR results, the conformation of RAP in the constrained state is different from that of MAP. The increased content of amorphous phase in the temperature range from 120 to $192^{\circ} \mathrm{C}$ is ascribed to the relaxation of RAP, rather than the melting of defective crystals. When the PTT is heated to a temperature above $192^{\circ} \mathrm{C}$, the recrystallization/crystal perfection of original defective lamellae occurs without a pre-melting process, which leads to an increase in lamellar thickness and probably connects two adjacent lamellar stacks. This is responsible for an increase in crystallinity as well as a higher major melting temperature.
\end{abstract}

poly(trimethylene terephthalate), relaxation of rigid amorphous phase, recrystallization

Citation: Chen Z, Yan S K. Structural variation of melt-crystallized PTT during the heating process revealed by FTIR and SAXS. Chin Sci Bull, 2013, 58: 328-335, doi: 10.1007/s11434-012-5589-x

Among the family of aromatic polyester, poly(trimethylene terephthalate) (PTT) has been attracting much attention owing to its excellent resilience [1-3] and processing characteristics in comparison with poly(ethylene terephthalate) (PET) and poly(butylene terephthalate) (PBT). Morphology and thermal behavior of a crystalline PTT are usually very complicated and only one crystal modification with a triclinic unit cell has been identified so far [4,5]. It has been reported that the multiple melting behaviors of PTT vary with their preparation conditions revealed by differential scanning calorimetry (DSC) [6-9]. The multiple melting peaks are mainly explained by (i) the melting of crystalline entities with different stability and/or (ii) the meltingrecrystallization-remelting of the imperfect crystals. However, for the PTT sample prepared by cooling from melt to room temperature at a rate of $-10^{\circ} \mathrm{C} / \mathrm{min}$, there is little evidence to support the mechanism of melting of crystalline

*Corresponding author (email: skyan@mail.buct.edu.cn) entities with different stability. An ordered exothermal peak between the minor endothermic peak and the major melting peak has been revealed by Pyda et al. [10] during the heating process of PTT with high crystallinity. This report seems to support the melting-recrystallization-remelting mechanism. However, it should be noticed that the structural perfection of polymer crystals depends strongly on the crystallization process. It is well documented that the structure of cold crystallized polymer crystals is generally less perfect compared to those melt-crystallized at relatively higher temperature. Taking this into account, it is easier for the melting-recrystallization-remelting to take place than the melt-crystallized samples.

It should be pointed out that a three phase morphological model has been proposed, which has also been observed for PET [11-15] and PBT [16-19]. The three phase structure of PTT is described as crystalline lamella, mobile amorphous phase (MAP) between lamellae and rigid amorphous phases (RAP) associated with the crystalline-amorphous interface 
[20-24]. The MDSC results of Pyda et al. [10] suggest, however, that there is no or little rigid amorphous PTT when it is cooled down from the melt to room temperature at a rate of $-10^{\circ} \mathrm{C} / \mathrm{min}$. In order to investigate the structural development and the corresponding thermal behavior of PTT cooled from the melt to room temperature at a rate of $-10^{\circ} \mathrm{C} / \mathrm{min}$, techniques includes Fourier transform infrared spectroscopy (FTIR) and X-ray scattering and diffraction were employed in the present work.

FTIR is sensitive to both the chain conformation and the local molecular environment of polymers and has been extensively used as a convenient and powerful tool for in situ investigating the phase transition [25-28]. For PTT, assignments of crystalline and amorphous sensitive bands in FTIR have been shown in the literatures [29-31]. The content of crystalline phase obtained from this method shows a good proportion to the crystallinity from the density measurement.

Small angle X-ray scattering (SAXS) displays the structural parameters of crystalline and amorphous phase by the difference of electron density distribution and follows the structural variation during the heating process [32-34]. Moreover, wide angle X-ray diffraction (WAXD) is able to provide the information of crystalline region such as lattice spacing and crystallinity $[35,36]$.

\section{Experimental}

\subsection{Samples}

Poly(trimethylene terephthalate) Corterra ${ }^{\mathrm{TM}}$ CP509201 pellets synthesized by Shell Chemicals Co. were kindly supplied by Professor J. Sheng of Tianjin University. The intrinsic viscosity was $0.91 \mathrm{dL} / \mathrm{g}$ measured in 60/40 phenol/ tetrachloroethane at $303 \mathrm{~K}$. Prior to experiments, PTT pellets was dried for $10 \mathrm{~h}$ under vacuum at $100^{\circ} \mathrm{C}$.

\subsection{Measurements}

DSC measurements were carried out with a TA Instrument DSC Q2000 which was purged with a nitrogen gas flow of $50 \mathrm{~mL} / \mathrm{min}$. PTT samples weighed $(5 \pm 0.3) \mathrm{mg}$ were subjected to the DSC measurements. The samples were heated to $280^{\circ} \mathrm{C}$ firstly and kept at this temperature for $5 \mathrm{~min}$ to remove the thermal history completely. Then, the samples were cooled down to room temperature at a rate of $-10^{\circ} \mathrm{C} / \mathrm{min}$. The obtained samples were subsequently used to different measurements. Before measurements, the instrument was calibrated according to the requirements for different experiments.

Film samples of PTT prepared for FTIR measurements were solution-cast on $\mathrm{KBr}$ windows from a $1 \mathrm{wt} \%$ 60/40 $(\mathrm{v} / \mathrm{v})$ phenol/tetrachloroethane solution. The films were dried under vacuum for $24 \mathrm{~h}$ at $60^{\circ} \mathrm{C}$ to remove the residual solvent before thermal treatments. FTIR spectra were obtained with a Bruker tensor 27 spectrometer equipped with a DTGs detector. The samples were heated from 30 to $246^{\circ} \mathrm{C}$ at a heating rate of $2^{\circ} \mathrm{C} / \mathrm{min}$. FTIR spectra were recorded at $2^{\circ} \mathrm{C}$ intervals and obtained by averaging 32 scans at $4 \mathrm{~cm}^{-1}$ resolution. Peak heights were used for data analysis due to the presence of some heavily overlapped peaks resulted in inconvenient calculation for the precise integrated intensity.

Synchrotron SAXS experiments were performed at BL16B1 in Shanghai Synchrotron Radiation Facility (SSRF) in China. An INSTEC hot stage (STC200) was used to fulfill the heating process during the measurements. The SAXS data were collected using a 2D MarCCD165 detector and accumulated in time frames of $53 \mathrm{~s}$. The wavelength of radiation was $1.54 \AA$ and the distance between sample and detector (SDD) was set as $2.935 \mathrm{~m}$. Silver behenate $\left(\mathrm{AgC}_{22} \mathrm{H}_{43} \mathrm{O}_{2}\right)$ was used as standard material for calibration of the scattering vector. The SAXS data were recorded at each indicated temperature during the heating process for specimens cooled at $-10^{\circ} \mathrm{C} / \mathrm{min}$. The heating rate was $2^{\circ} \mathrm{C} / \mathrm{min}$. Those PTT films of $1 \mathrm{~mm}$ thickness prepared by hot compression of the melt were wrapped with polyimide film and then sandwiched between copper sheets with a hole for the incident beam. Due to the variation of thickness of the samples, the copper sheets were employed.

The SAXS data were converted to 1D SAXS profiles and background subtraction was carried out before the Lorentz-correction was performed.

The long period was calculated from eqs. (1) and (2):

$$
\begin{aligned}
& q=4 \pi \sin \theta / \lambda, \\
& 2 d \sin \theta=n \lambda .
\end{aligned}
$$

The scattering invariant $Q$ corresponding to the crystallinity is defined as

$$
Q=\int_{0}^{\infty} I(q) q^{2} \mathrm{~d} q
$$

where $I$ is the scattering intensity and $q$ is the scattering vector. For a two-phase system, the invariant $Q$ can also be written as

$$
Q=V \varphi_{\mathrm{st}} \varphi_{\mathrm{c}}\left(1-\varphi_{\mathrm{c}}\right) \Delta \rho_{\mathrm{e}}{ }^{2},
$$

where $V$ is the irradiated sample volume, $\varphi_{\text {st }}$ is the volume fraction which has been transformed into lamellar stacks, $\varphi_{\mathrm{c}}$ is the crystalline fraction within the stacks, and $\Delta \rho_{\mathrm{e}}{ }^{2}$ is the density difference of the crystalline and amorphous regions.

An X-ray diffraction PHILIPS X'Pert MPD with a hot stage was used for the in situ measurement of WAXD. All temperature-dependent WAXD data were recorded at each indicated temperature in the range of $5^{\circ}-35^{\circ}$, and the heating rate was $0.03^{\circ} \mathrm{C} / \mathrm{min}$.

\section{Results and discussion}

Figure 1 shows the DSC scans of the PTT samples with 

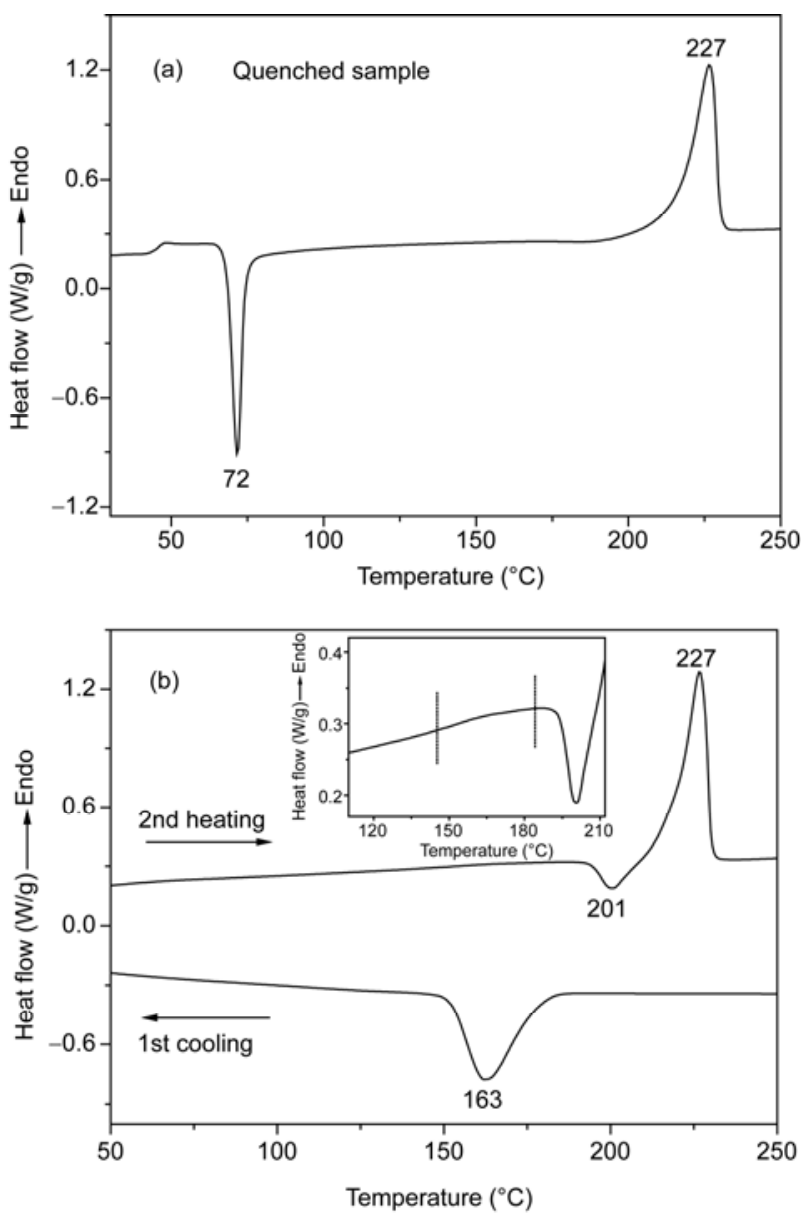

Figure 1 DSC scans of (a) a melt-quenched PTT sample heated from room temperature to $280^{\circ} \mathrm{C}$ and (b) a PTT sample cooled first from the melt to room temperature and then heated from room temperature to $280^{\circ} \mathrm{C}$. The heating and cooling rates were $10^{\circ} \mathrm{C} / \mathrm{min}$. The inset in Figure $1(\mathrm{~b})$ is the enlarged region of DSC heating scan in the temperature range of 110 $212^{\circ} \mathrm{C}$.

different thermal histories. It can be seen that the thermal behavior of PTT depends strongly on the thermal history of the samples. There are clearly an exothermic peak at $72^{\circ} \mathrm{C}$ and an endothermic peak at $227^{\circ} \mathrm{C}$ during the heating scan of the melt-quenched PTT sample (Figure 1(a)), corresponding to the cold crystallization of the sample and the melting of the resultant crystals. For the sample cooled from melt at a rate of $-10^{\circ} \mathrm{C} / \mathrm{min}$ to room temperature (Figure 1(b)), a sharp and well defined crystallization peak appears at $163^{\circ} \mathrm{C}$ in the DSC cooling scan, indicating the occurrence of crystallization. In the heating scan, a tiny exothermic peak appears at $201{ }^{\circ} \mathrm{C}$. The presence of the exothermic peak at $201^{\circ} \mathrm{C}$ may originate from (i) cold crystallization of PTT remained in the amorphous state during cooling; (ii) meltingrecrystallization and/or crystal perfection of the defective crystals formed during cooling. Considering that the meltquenched PTT cold-crystallizes at around $72^{\circ} \mathrm{C}$ during heating, further cold crystallization of the amorphous fraction remained in the non-isothermally crystallization process at ca. $201^{\circ} \mathrm{C}$ is very difficult to take place. Also the sharp and well defined crystallization peak at $163^{\circ} \mathrm{C}$ in the DSC cooling scan indicates that the crystallization of PTT is essentially finished during the cooling process from melt to room temperature. Therefore, the mechanism of recrystallization/crystal perfection is believed to be responsible for presence of the exothermic peak at $201^{\circ} \mathrm{C}$. In addition, in the enlarged insert of Figure 1(b), an endothermic phenomenon between dash lines is observed just prior to the exothermal peak. Pyda et al. [10] explained it by the melting of small and defective crystallites base on their MDSC results. To further disclose the structural changes between glass transition and ultimate melting temperature, the heating process of PTT sample obtained by cooling its melt to room temperature at $-10^{\circ} \mathrm{C} / \mathrm{min}$ is studied in detail here via IR technique.

Figure 2 shows the FTIR spectra evolution of the nonisothermally crystallized PTT film at $2{ }^{\circ} \mathrm{C}$ intervals during the heating process. The enlarged spectral regions of $1750-1690 \mathrm{~cm}^{-1}$ and $840-790 \mathrm{~cm}^{-1}$ are plotted in the insert of Figure 2. To avoid over-saturated intensities of IR bands for relatively thicker films prepared by thermo-compression, the solution-cast PTT film is prepared in our experiment, which enables the suitable intensities of characteristic bands in IR spectra for analysis. The IR bands assignment is listed in Table 1, according to the refs. [21-23]. From Figure 2, the change of FTIR spectra is evident, reflecting the structural change of PTT during the heating process. The peak heights of characteristic bands as a function of temperature are displayed in Figure 3(a) and (b), respectively, which is indicative of intensity changes. Here, four sensitive bands generated by the vibration of $\mathrm{CH}_{2}$ and $\mathrm{C}=\mathrm{O}$ groups are adopted. The bands at 1358 and $815 \mathrm{~cm}^{-1}$ are assigned to the gauche $\mathrm{CH}_{2}$ wagging vibration in crystalline phase and the trans $\mathrm{CH}_{2}$ trans rocking vibration in amorphous phase, respectively. These two bands are isolated and convenient for analysis. The bands at 1723 and $1711 \mathrm{~cm}^{-1}$ are attributed to the $\mathrm{C}=\mathrm{O}$ stretching bend in amorphous phase and crystalline phase, respectively. Although the $\mathrm{C}=\mathrm{O}$ stretching bands are overlapped heavily, they are not affected by other bands and the intensities are large enough to show the structural change.

From Figure 3(a), one can see that conspicuous transitions of both bands at 1358 and $815 \mathrm{~cm}^{-1}$ are addressed in the heating process. First of all, below $200^{\circ} \mathrm{C}$, the intensity of the $1358 \mathrm{~cm}^{-1}$ band decreases linearly with increasing temperature due to the reduction in molar absorptivity which is usually seen in many polymers. Whereas, the intensity of the amorphous band at $815 \mathrm{~cm}^{-1}$ increases rapidly above $120^{\circ} \mathrm{C}$. Similar change is also observed for the 1723 $\mathrm{cm}^{-1}$ band in amorphous state and the $1711 \mathrm{~cm}^{-1}$ band in crystalline state, respectively. This phenomenon can be explained by the following way. During the quick crystallization process by cooling the melted PTT at a rate of $-10^{\circ} \mathrm{C} / \mathrm{min}$, amorphous molecules adjacent to lamellae are confined, which is defined to the rigid amorphous phase. It 


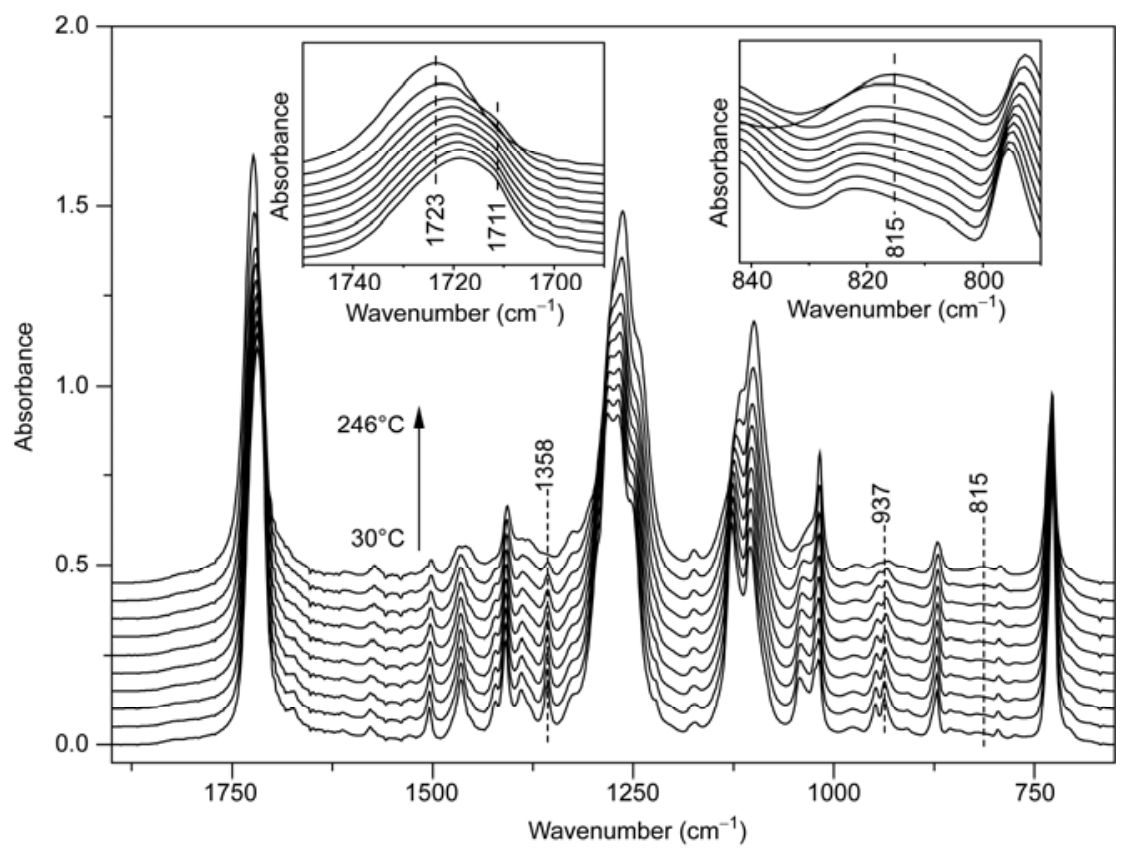

Figure 2 IR spectra of a PTT sample in the region of $1900-650 \mathrm{~cm}^{-1}$ during the heating process from 30 to $246^{\circ} \mathrm{C}$. The sample was prepared by cooling the PTT from $280^{\circ} \mathrm{C}$ to room temperature at a rate of $-10^{\circ} \mathrm{C} / \mathrm{min}$. The heating rate was $2^{\circ} \mathrm{C} / \mathrm{min}$. The insets show the enlarged region of $1750-1690 \mathrm{~cm}^{-1}$ generated by the $\mathrm{C}=\mathrm{O}$ stretching vibration and the region of $842-790 \mathrm{~cm}^{-1}$ generated by the trans $\mathrm{CH}_{2}$ trans rocking vibration in amorphous phase, respectively.

Table 1 Band assignments of PTT film

\begin{tabular}{cl}
\hline Wavenumber $\left(\mathrm{cm}^{-1}\right)$ & \multicolumn{1}{c}{ Assignment } \\
\hline 1723 & $\mathrm{C}=\mathrm{O}$ stretching in amorphous \\
1711 & $\mathrm{C}=\mathrm{O}$ stretching in crystalline \\
1358 & gauche $\mathrm{CH}_{2}$ wagging in crystalline \\
937 & gauche $\mathrm{CH}_{2}$ rocking in amorphous \\
815 & trans $\mathrm{CH}_{2}$ rocking in amorphous \\
\hline
\end{tabular}

has been proposed that the rigid amorphous fraction neither contributes to the calorimetrically observed glass transition, nor is able to further adjust the conformation to ordered structure $[21,23,37]$. When PTT is heated to $120^{\circ} \mathrm{C}$ or higher again, molecules in the rigid amorphous phase have enough energy to overcome the restriction exerted by the adjacent crystalline fraction. Its conformation transforms to the same as that in the mobile amorphous phase which have relaxed above the glass transition temperature. The relaxation of RAP only increases the intensities of amorphous bands at 1723 and $815 \mathrm{~cm}^{-1}$ but does not affect the content of crystalline fraction corresponding to the intensity of $1711 \mathrm{~cm}^{-1}$ band and $1358 \mathrm{~cm}^{-1}$ band. This indicates that molecules in RAP neither behave like random coils as that in MAP, nor align as that in ordered crystalline phase. Actually, the above mentioned structural change is also clearly revealed in the enlarged DSC curve plotted in the insert of Figure 1(b). One can see a very small and broad endothermic slope in this temperature range marked by the dash lines. It reveals that the relaxation of RAP accompanies an endothermic

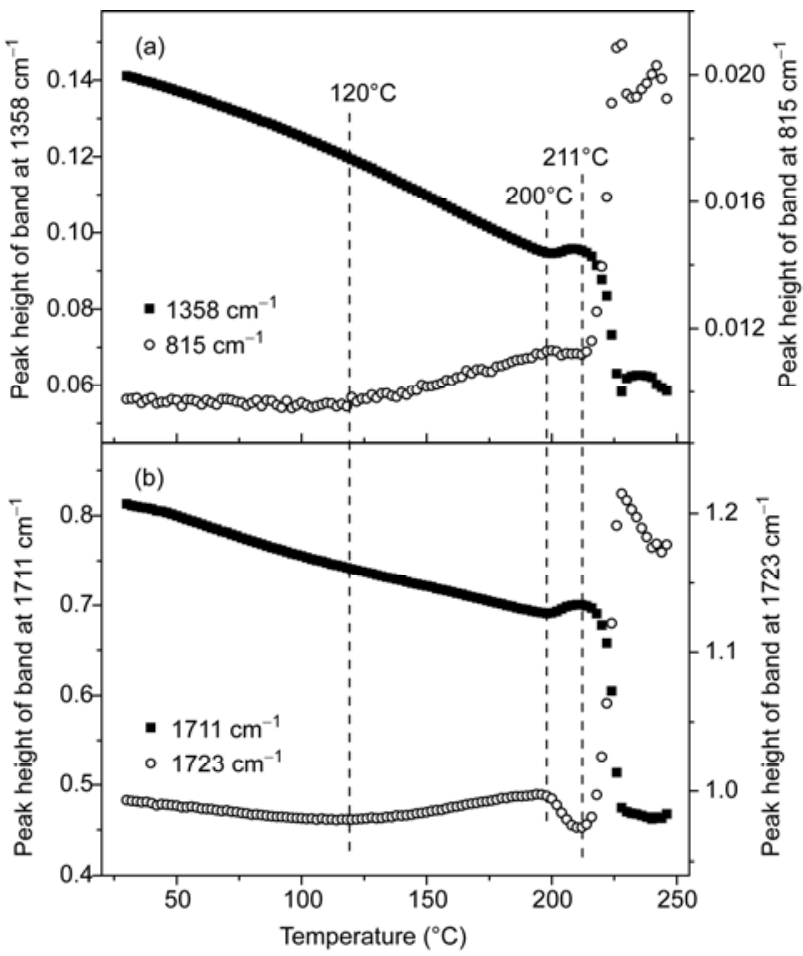

Figure 3 Peak heights of (a) the crystalline band at $1358 \mathrm{~cm}^{-1}$ and the amorphous band at $815 \mathrm{~cm}^{-1}$, (b) the crystalline band at $1711 \mathrm{~cm}^{-1}$ and the amorphous band at $1723 \mathrm{~cm}^{-1}$ as a function of temperature during the heating process of a PTT sample prepared by cooling from melt to room temperature at a rate of $-10^{\circ} \mathrm{C} / \mathrm{min}$.

effect. Therefore, the structure of rigid amorphous phase is different from that of MAP. Even though the motion of 
molecules is prevented by neighboring lamellae and the arrangement is far from the ordered structure, the conformation of $-\mathrm{CH}_{2}-\mathrm{CH}_{2}-\mathrm{CH}_{2}-$ segment has deviated from trans conformation and the relative position between aromatic ring and $\mathrm{C}=\mathrm{O}$ group has also differed from that in the mobile amorphous phase. These disordered and restricted molecules will overcome the restriction and improve the structure if the relatively lower thermal energy is supplied. This explanation differs from the proposal of the pre-melting of imperfect crystals by Pyda et al. [10], which may origin from the employed different techniques and molecular weight of PTT.

With further increase of temperature, the intensities of all bands in Figure 3(a) and (b) change abruptly. The intensities of $1358 \mathrm{~cm}^{-1}$ band and $1711 \mathrm{~cm}^{-1}$ band increase evidently, and those of $815 \mathrm{~cm}^{-1}$ band and $1723 \mathrm{~cm}^{-1}$ band decrease accordingly from 200 to $211^{\circ} \mathrm{C}$. This implies an increment in crystallinity of PTT, which is in agreement with the appearance of an exothermal peak in this temperature range in DSC results. The discrepancy in transition temperature between FTIR $\left(200^{\circ} \mathrm{C}\right)$ and DSC $\left(193^{\circ} \mathrm{C}\right)$ results may be due to the different working principles. The exothermal ordering peak in DSC may be related to a solid-solid phase transition of crystal such as that happened for the PLLA [25]. This is, however, not the case for PTT. Our WAXD experiment identifies that only one crystal modification is shown during the whole heating process (Figure 4). So the increasing crystallinity in this region is ascribed to the increment of ordered structure with the same crystal lattice. Above $211^{\circ} \mathrm{C}$, the intensities of crystalline bands decrease dramatically accompanied by a rapid intensities increase of the amorphous bands, indicating the melting behavior of PTT crystals. It is consistent with the appearance of a well defined endothermic peak in the DSC heating scan. In summary, from 120 to $200^{\circ} \mathrm{C}$, the increasing content of amorphous phase is not at the cost of melting of defective crystals or

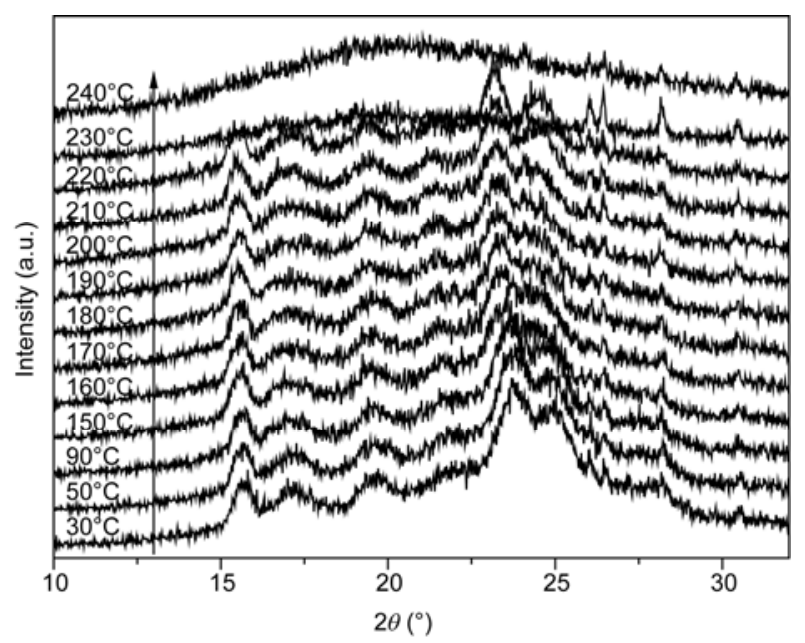

Figure 4 Temperature-dependent WAXD profiles during the heating process of PTT sample cooled from the melt to room temperature. less ordered structure. This is because there is no deviation for the intensities of crystalline bands. It is only due to the relaxation of the rigid amorphous phase. And then, the increase in crystallinity from 200 to $211^{\circ} \mathrm{C}$ is usually attributed to the recrystallization/crystal perfection behavior. The DSC and SAXS analysis about this process are shown in the following section.

It is widely recognized that the heating rate of DSC scan can affect the thermal behavior of a polymer. Figure 5 shows the DSC heating curves with different rates from 2 to $50^{\circ} \mathrm{C} / \mathrm{min}$ for the PTT samples cooled from melt to room temperature. With increasing heating rate, the melting peak $T_{\mathrm{m}}$ shifts from 229 to $224^{\circ} \mathrm{C}$, as marked by the dash line. This phenomenon indicates that recrystallization/crystal perfection takes place in the exothermal ordering region before the ultimate melting peak. During the cooling process with a rate of $-10^{\circ} \mathrm{C} / \mathrm{min}$, some defective crystals or less ordered structure formed. They will be improved in the subsequent heating process. More perfect crystalline structure and a larger number of crystals can form during slower heating process, which is due to the fact that molecular chains have longer time to assemble into more ordered structures. Therefore, the resultant perfect crystals exhibit a higher $T_{\mathrm{m}}$. However, the recrystallization temperature $\left(T_{\mathrm{rc}}\right)$ is not influenced by the heating rate. Generally, at lower rates the polymer chains have more time to change conformation and organize into ordered structures, so crystallization will occur at lower temperatures. In the present work, the unusual phenomenon about the recrystallization temperature is still unclear and it will be further investigated in other works.

Temperature-dependent SAXS profiles of the non-isothermally crystallized PTT sample were recorded during the heating process. The Lorentz-corrected SAXS patterns are shown in three temperature regions in order to ascertain the scattering peak clearly, see Figure 6 . In the temperature

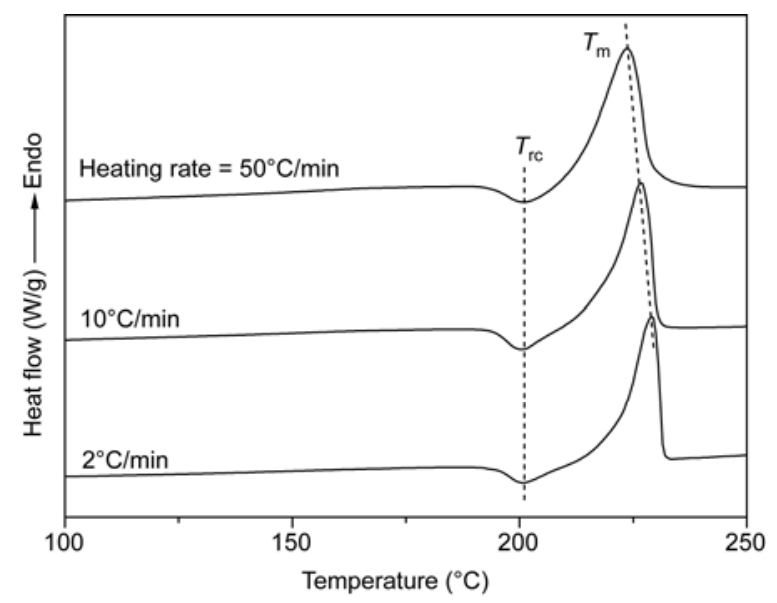

Figure 5 DSC curves during the heating process of PTT cooled from the melt to room temperature, with various heating rates, i.e., 2, 10 and $50^{\circ} \mathrm{C} / \mathrm{min}$, respectively. 


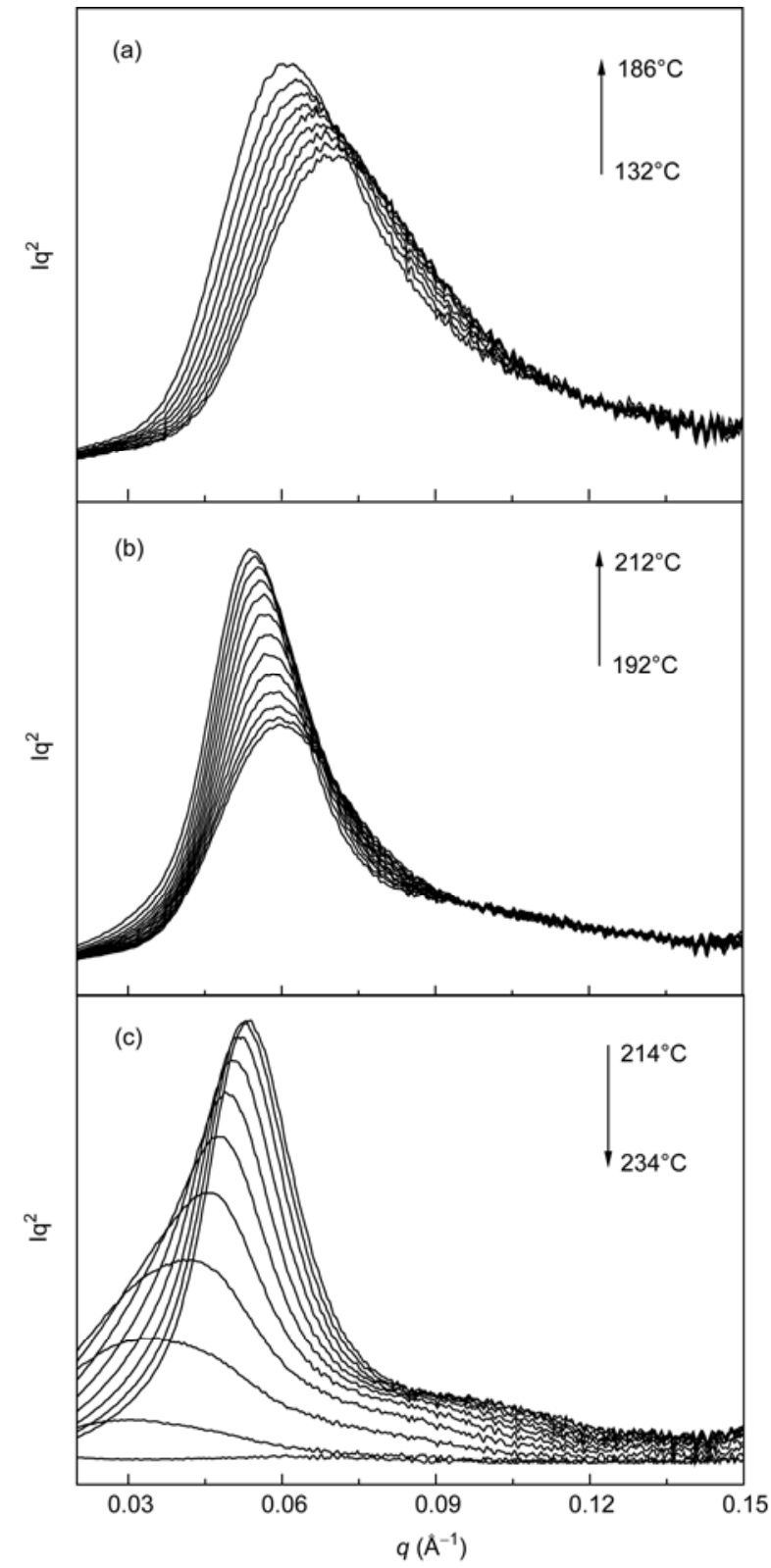

Figure 6 Temperature-dependent SAXS profiles after Lorentz-correction of PTT sample cooled from the melt to room temperature, recorded during the heating process at a rate of $2^{\circ} \mathrm{C} / \mathrm{min}$ (a) 132 to $186^{\circ} \mathrm{C}$; (b) 192 to $212^{\circ} \mathrm{C}$; (c) 214 to $234^{\circ} \mathrm{C}$.

range of $132-186^{\circ} \mathrm{C}$, as shown in Figure 6(a), the scattering peak shifts to a smaller $q$ gradually and a slight intensity change is also recognized. When the sample is heated above $192^{\circ} \mathrm{C}$ but below $212^{\circ} \mathrm{C}$, see Figure $6(\mathrm{~b})$, the scattering intensity increases dramatically, indicating an increase in crystallinity of PTT. Moreover, with increasing the temperature, more symmetric first-order peak with smaller half width is observed in the SAXS profiles. Additionally, a second-order scattering peak becomes more discernible, situated at $q$ value of $1: 2$ relative to the first-order scattering maximum. These new features of SAXS profiles demonstrate that narrower distribution of lamellar thickness and more ordered lamellar structure are presented. When the sample was heated above $214^{\circ} \mathrm{C}$, profiles become broader and broader, and then the Bragg peak disappears at $234^{\circ} \mathrm{C}$. The slight difference in transition temperature with those obtained from other measurements is due to the different principles of various techniques.

From the Lorentz-corrected SAXS profiles, changes in the long period $L$ and the scattering invariant $Q$ during the heating process can be obtained and shown in Figure 7. From Figure $7(\mathrm{~b})$, one can see that, below $160^{\circ} \mathrm{C}$, the invariant $Q$ is linear with temperature. From 160 to $192^{\circ} \mathrm{C}$, the scattering invariant $Q$ increases, however, in a slower way as compared with that below $160^{\circ} \mathrm{C}$. But the long period increases with a constant slope from 132 to $192^{\circ} \mathrm{C}$ in Figure 7(a). With further increase of temperature, in region from 192 to $214^{\circ} \mathrm{C}$, an abrupt increase in scattering invariant $Q$ is observed, and the long period also increases in a bit quicker trend than before. Then an abrupt decrease of scattering invariant $Q$ and an increase of long period are seen when the temperature is over $214^{\circ} \mathrm{C}$. These changes in the long period and the scattering invariant $Q$ together with SAXS profiles well conform and complement the FTIR results.

First of all, the deflection of $Q$ from 160 to $192^{\circ} \mathrm{C}$ should results from the relaxation of the rigid amorphous phase as

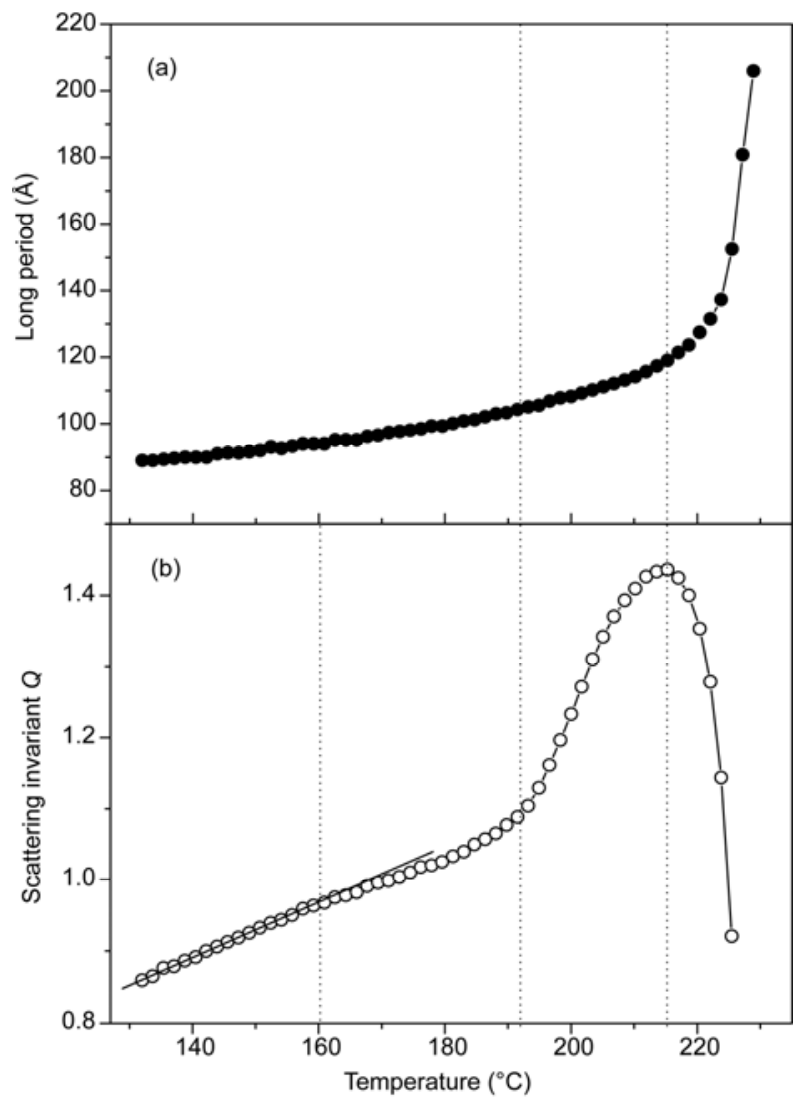

Figure 7 Evolution of the long period $(L)$ (a) and the scattering invariant $Q$ (b) of PTT sample cooled from the melt to room temperature during the heating process. 
described in IR section. As mentioned in the experimental section, the scattering invariant $Q$ is positively proportional to the irradiated sample volume $V$, the volume fraction $\varphi_{\text {st }}$, the production of $\varphi_{\mathrm{c}}$ and $\left(1-\varphi_{\mathrm{c}}\right)$ and the density difference of the crystalline and amorphous regions $\Delta \rho_{\mathrm{e}}{ }^{2}$. The increased $Q$ is mainly considered as the contribution of increased $\Delta \rho_{\mathrm{e}}^{2}$ when no other transition occurs except for the thermal expansion during the heating process. This is reasonable since the delatation of amorphous phase is larger than that of crystalline phase, which leads to a greater $\Delta \rho_{\mathrm{e}}{ }^{2}$ when the sample is heated. The relaxation of molecules from rigid amorphous phase to mobile amorphous state, suggested by IR and DSC results above, first results in an increase of the mobile amorphous content and meanwhile an even larger expansion of the enlarged amorphous phase with temperature. All these lead to a further increase of the long period, which corresponds to a decrease in $\varphi_{\mathrm{c}}$ when the lamellar thickening is neglected. As a result, the increase of invariant $Q$ has been slowed. However, based on IR results, the amorphous content has already begun to increase from $120^{\circ} \mathrm{C}$. This indicates FTIR shows a higher sensitivity in detecting the conformation of molecules than SAXS. Moreover, it is suggested that the rigid amorphous phase of PTT forms not only in the crystallization process but also during the subsequent cooling process. So during the reheating, the relaxation of RAP appears earlier than the former crystallization temperature.

Above $192^{\circ} \mathrm{C}$, the scattering invariant $Q$ increases abruptly. An increment about $32 \%$ over an interval of $22^{\circ} \mathrm{C}$ far exceeds the contribution by increased $\Delta \rho_{\mathrm{e}}{ }^{2}$ owing to the thermal expansion. Therefore, an increment in crystalline fraction, i.e., the occurrence of further crystallization is demonstrated in this temperature region. This is in good agreement with DSC and FTIR results. It may experience a secondary crystallization with new lamellae inserting between the pre-extent lamellae or a recrystallization/crystal perfection of the defective crystals formed during the cooling process. In the present case, it is impossible for the first behavior since it will result in a decrease in long period. Figure 7(a) shows an increasing in long period in this temperature region. Therefore, it is reasonable that the increased crystallinity is due to the further improvement on the original small and thin lamellae. According to FTIR results, there is no intensity decrease of the crystalline bands in this region, so the recrystallization/crystal perfection directly follows the pre-extent lamellae other than partial melting first. Because the recrystallization temperature is higher than the former crystallization temperature, this transition leads to an increase in lamellar thickness, i.e., an increased $\varphi_{\mathrm{c}}$. And the volume fraction $\varphi_{\mathrm{st}}$ will increase simultaneously if the perfected lamellae are located between two original stacks and bring about a new continuous lamella/ amorphous structure. Consequently, the scattering invariant $Q$ value enhances abruptly as a result of the recrystallization/crystal perfection. When temperature is over $214^{\circ} \mathrm{C}$, major sequential melting leads to an abrupt increase in the long period $L$ and a decrease in the scattering invariant $Q$ displayed in Figure 7.

\section{Conclusions}

In summary, the structural evolution of crystalline PTT formed during cooling from the melt to room temperature at a rate of $-10^{\circ} \mathrm{C} / \mathrm{min}$ has been studied in detail by the combination of DSC, FTIR and WAXD/SAXS experiments in the subsequent heating process.

(1) During the heating process, a gradual increment in intensities of amorphous bands is observed from 120 to $200^{\circ} \mathrm{C}$ based on FTIR results. It is illustrated that the elevated content of amorphous phase in this temperature range is not at the expense of crystalline quantity because there is no change in intensities of crystalline bands below $200^{\circ} \mathrm{C}$. The extra amorphous content is obtained through the relaxation of rigid amorphous phase. The molecular conformation differs from that in the mobile amorphous phase. This relaxation behavior is accordant with the small endothermic peak in the enlarged DSC curve.

(2) DSC and FTIR results disclose that the crystallinity increases dramatically during the following temperature region from 192 to $214^{\circ} \mathrm{C}$. SAXS data identify that the increased crystallinity is ascribed to the recrystallization/ crystal perfection process of original defective lamellae, rather than the insertion of thinner lamellae between preexistent lamellae.

This work was supported by the National Natural Science Foundation of China (50773088). The synchrotron SAXS experiments were supported by Shanghai Synchrotron Radiation Facility in China (j10sr0008 and 08sr0188).

1 Jakeways R, Ward I M, Wilding M A, et al. Crystal deformation in aromatic polyesters. J Polym Sci Polym Phys, 1975, 13: 799-813

2 Ward I M, Wilding M A, Brody H. The mechanical properties and structure of poly $(m$-methylene terephthalate) fibers. J Polym Sci Polym Phys, 1976, 14: 263-274

$3 \mathrm{Wu} \mathrm{G}, \mathrm{Li} \mathrm{H} \mathrm{W,} \mathrm{Wu} \mathrm{Y} \mathrm{Q,} \mathrm{et} \mathrm{al.} \mathrm{Structure} \mathrm{and} \mathrm{property} \mathrm{studies} \mathrm{of}$ poly(trimethylene terephthalate) high-speed melt spun fibers. Polymer, 2002, 43: 4915-4922

4 Desborough I J, Hall I H, Neisser J Z. The structure of poly(trimethylene terephthalate). Polymer, 1979, 20: 545-552

5 Poulin-Dandurand S, Pérez S, Revol J F, et al. The crystal structure of poly(trimethylene terephthalate) by X-ray and electron diffraction. Polymer, 1979, 20: 419-426

6 Chung W T, Yeh W J, Hong P D. Melting behavior of poly(trimethylene terephthalate). J Appl Polym Sci, 2002, 83: 2426-2433

7 Wu P L, Woo E M. Correlation between melting behavior and ringed spherulites in poly(trimethylene terephthalate). J Polym Sci Polym Phys, 2003, 41: 80-93

8 Srimoaon P, Dangseeyun N, Supaphol P. Multiple melting behavior in isothermally crystallized poly(trimethylene terephthalate). Eur Polym J, 2004, 40: 599-608

9 Zeng W, Li H H, Liu T X, et al. A study on the double melting behavior of poly(trimethylene terephthalate). Chin Sci Bull, 2008, 53: 2145-2155 
10 Pyda M, Boller A, Grebowicz J, et al. Heat capacity of poly(trimethylene terephthalate). J Polym Sci Polym Phys, 1998, 36: 2499-2511

11 Song M. Rigid amorphous phase and low temperature melting endotherm of poly(ethylene terephthalate) studied by modulated differential scanning calorimetry. J Appl Polym Sci, 2001, 81: 2779-2785

12 Alvarez C, Šics I, Nogales A, et al. Structure-dynamics relationship in crystallizing poly(ethylene terephthalate) as revealed by time-resolved X-ray and dielectric methods. Polymer, 2004, 45: 3953-3959

13 Di Lorenzo M L, Righetti M C, Cocca M, et al. Coupling between crystal melting and rigid amorphous fraction mobilization in poly (ethylene terephthalate). Macromolecules, 2010, 43: 7689-7694

14 Righetti M C, Di Lorenzo M L, Tombari E, et al. The low-temperature endotherm in poly(ethylene terephthalate): Partial melting and rigid amorphous fraction mobilization. J Phys Chem B, 2008, 112: 42334241

15 Chen H P, Cebe P. Vitrification and devitrification of rigid amorphous fraction of PET during quasi-isothermal cooling and heating. Macromolecules, 2008, 42: 288-292

16 Cheng S Z D, Pan R, Wunderlich B. Thermal analysis of poly(butylene terephthalate) for heat capacity, rigid-amorphous content, and transition behavior. Die Makromolekulare Chemie, 1988, 189: 2443-2458

17 Righetti M C, Di Lorenzo M L. Melting process of poly(butylene terephthalate) analyzed by temperature-modulated differential scanning calorimetry. J Polym Sci Polym Phys, 2004, 42: 2191-2201

18 Righetti M C, Di Lorenzo M L, Angiuli M, et al. Structural reorganization in poly(butylene terephthalate) during fusion. Macromolecules, 2004, 37: 9027-9033

19 Pyda M, Nowak-Pyda E, Mays J, et al. Heat capacity of poly(butylene terephthalate). J Polym Sci Polym Phys, 2004, 42: 4401-4411

20 Hong P D, Chuang W T, Yeh W J, et al. Effect of rigid amorphous phase on glass transition behavior of poly(trimethylene terephthalate). Polymer, 2002, 43: 6879-6886

21 Shafee E E. Effect of aging on the mechanical properties of coldcrystallized poly(trimethylene terephthalate). Polymer, 2003, 44: 3727-3732

22 Kalakkunnath S, Kalika D S. Dynamic mechanical and dielectric relaxation characteristics of poly(trimethylene terephthalate). Polymer, 2006, 47: 7085-7094

23 Sanz A, Nogales A, Ezquerra $\mathrm{T}$ A, et al. Cold crystallization of poly(trimethylene terephthalate) as revealed by simultaneous WAXS, SAXS, and dielectric spectroscopy. Macromolecules, 2009, 43: 671679

24 Ma Q, Georgiev G, Cebe P. Constraints in semicrystalline polymers: Using quasi-isothermal analysis to investigate the mechanisms of formation and loss of the rigid amorphous fraction. Polymer, 2011, 52: 4562-4570

25 Zhang J M, Duan Y X, Sato H, et al. Crystal modifications and thermal behavior of poly(l-lactic acid) revealed by Infrared spectroscopy. Macromolecules, 2005, 38: 8012-8021

$26 \mathrm{Hu} \mathrm{Y}$, Zhang $\mathrm{J} \mathrm{M}$, Sato $\mathrm{H}$, et al. Multiple melting behavior of poly(3-hydroxybutyrate-co-3-hydroxyhexanoate) investigated by differential scanning calorimetry and infrared spectroscopy. Polymer, 2007, 48: 4777-4785

27 Duan Y X, Zhang J M, Shen D Y, et al. In situ FTIR studies on the cold-crystallization process and multiple melting behavior of isotactic polystyrene. Macromolecules, 2003, 36: 4874-4879

28 Yu L L, Gao B, Chen Z, et al. In situ FTIR investigation on phase transformations in BN nanoparticles. Chin Sci Bull, 2005, 50: 28272831

29 Ward I M, Wilding M A. Infra-red and Raman spectra of poly(mmethylene terephthalate) polymers. Polymer, 1977, 18: 327-335

30 Bulkin B J, Lewin M, Kim J. Crystallization kinetics of poly(propylene terephthalate) studied by rapid-scanning Raman spectroscopy and FT-IR spectroscopy. Macromolecules, 1987, 20: 830-835

31 Kim K J, Bae J H, Kim Y H. Infrared spectroscopic analysis of poly(trimethylene terephthalate). Polymer, 2001, 42: 1023-1033

32 Schmidtke J, Strobl G, Thurn-Albrecht T. A four-state scheme for treating polymer crystallization and melting suggested by calorimetric and small angle X-ray scattering experiments on syndiotactic olypropylene. Macromolecules, 1997, 30: 5804-5821

33 Hsiao B, Wang Z G, Yeh F, et al. Time-resolved X-ray studies of structure development in poly(butylene terephthalate) during isothermal crystallization. Polymer, 1999, 40: 3515-3523

34 Iijima M, Strobl G. Isothermal crystallization and melting of isotactic polypropylene analyzed by time- and temperature-dependent smallangle X-ray scattering experiments. Macromolecules, 2000, 33: 52045214

35 Sato H, Nakamura M, Padermshoke A, et al. Thermal behavior and molecular interaction of poly(3-hydroxybutyrate-co-3-hydroxyhexanoate) studied by wide-angle X-ray diffraction. Macromolecules, 2004, 37: 3763-3769

36 Zhang J M, Tashiro K, Tsuji H, et al. Disorder-to-order phase transition and multiple melting behavior of poly(l-lactide) investigated by simultaneous measurements of WAXD and DSC. Macromolecules, 2008, 41: 1352-1357

37 Fai Lau S, Suzuki H, Wunderlich B. The thermodynamic properties of polytetrafluoroethylene. J Polym Sci Polym Phys, 1984, 22: 379405

Open Access This article is distributed under the terms of the Creative Commons Attribution License which permits any use, distribution, and reproduction in any medium, provided the original author(s) and source are credited. 